\title{
Carnosine Inhibits (E)-4-Hydroxy-2-nonenal-Induced Protein Cross-linking: Structural Characterization of Carnosine-HNE Adducts
}

\author{
Yahua Liu, Guozhang Xu, and Lawrence M. Sayre
}

\section{Supporting Information}

\section{Table of Contents}

${ }^{1} \mathrm{H}$ NMR spectrum (300 MHz, $\left.\mathrm{CD}_{3} \mathrm{OD}\right)$ of HNE-aminoguanidine hydrazone ............S2

${ }^{13} \mathrm{C}$ APT NMR spectrum (75 MHz, $\mathrm{CD}_{3} \mathrm{OD}$ ) of HNE-aminoguanidine hydrazone ........S3

${ }^{1} \mathrm{H}$ NMR spectrum $\left(300 \mathrm{MHz}, \mathrm{CD}_{3} \mathrm{OD}\right)$ of HNE-carnosine crude reaction mixture.........S4

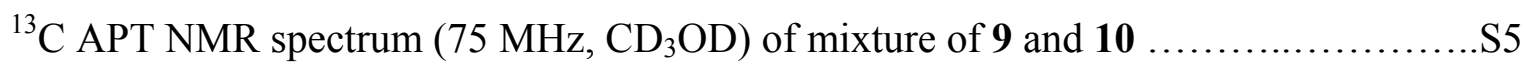

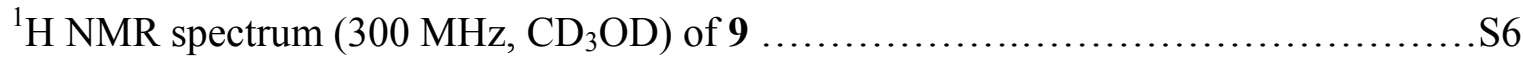

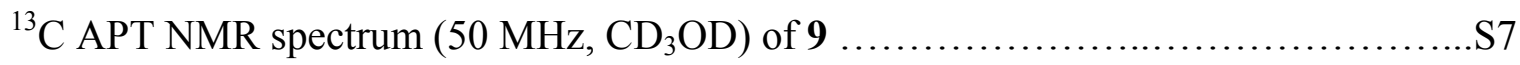

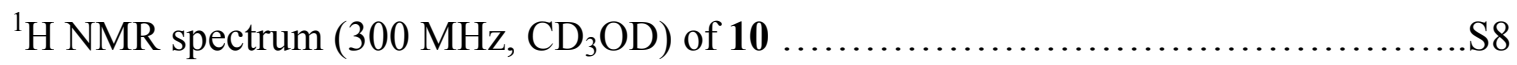

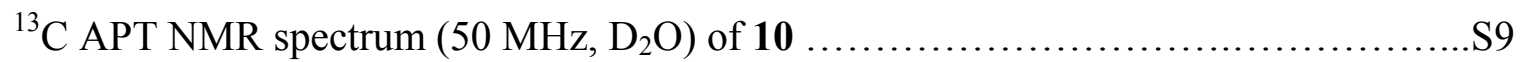

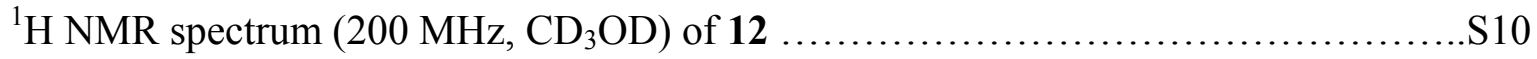

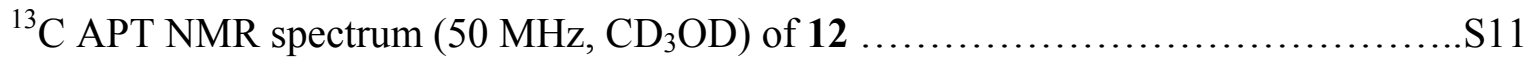

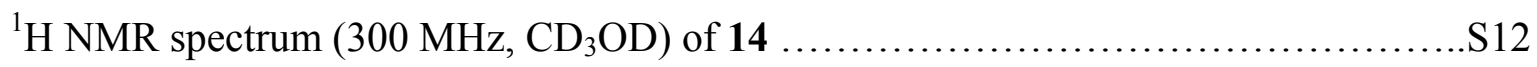

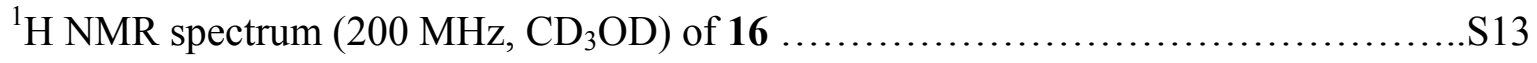

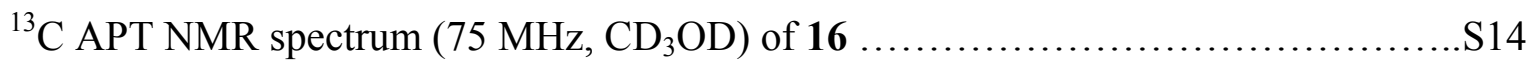

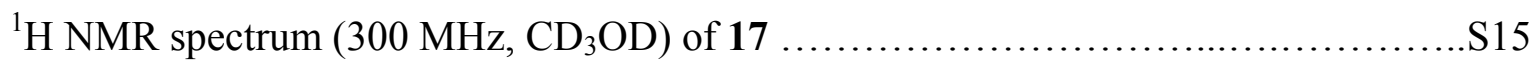





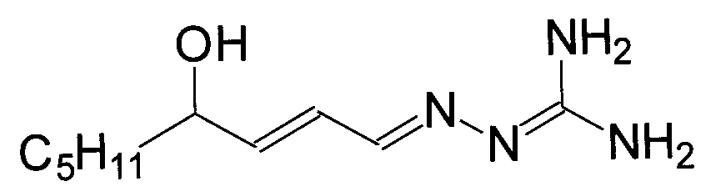

$1 \mathrm{H}$ NMR $(300 \mathrm{MHz})$ in $\mathrm{CD}_{3} \mathrm{OD}$

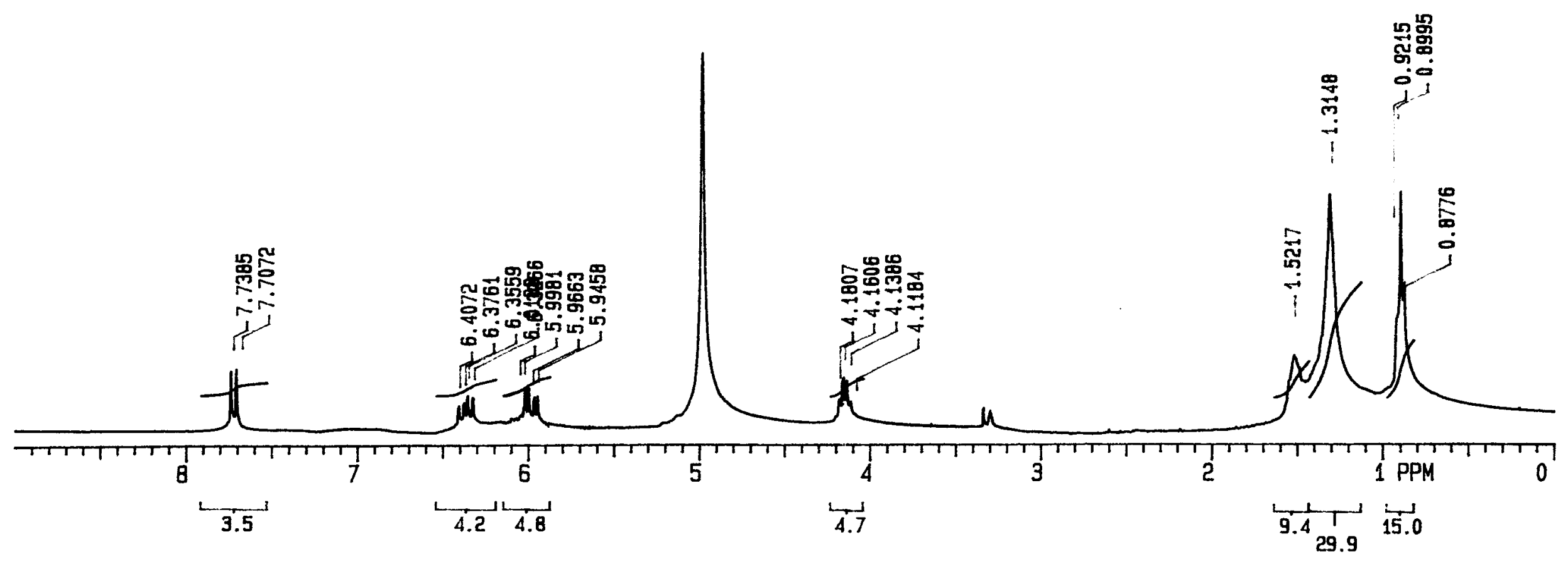


<smiles>[15CH2]C(O)/C=C/C=N/N=C(N)N</smiles>

${ }^{13} \mathrm{C}$ APT NMR $(75 \mathrm{MHz})$ in $\mathrm{CD}_{3} \mathrm{OD}$

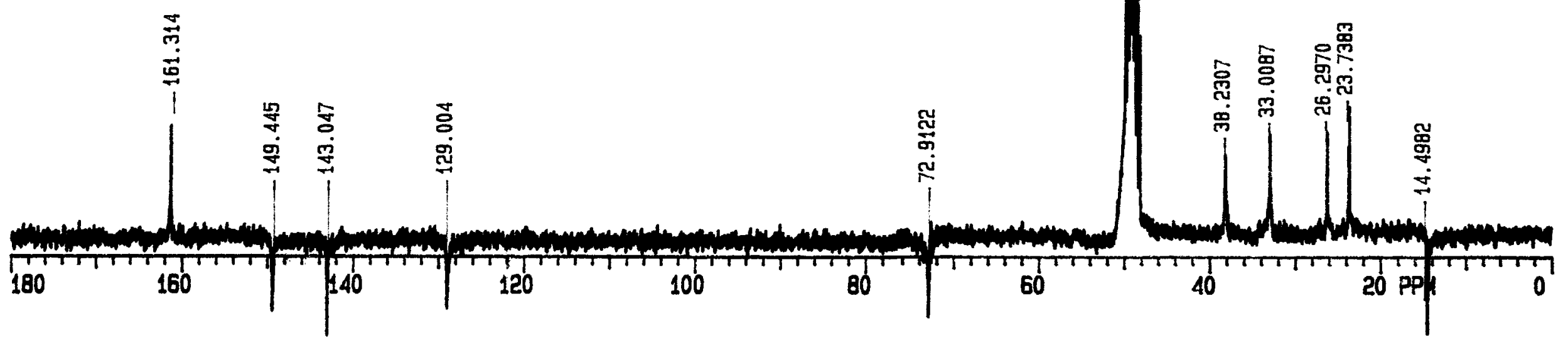


crude reaction product from the preparative reaction of HNE with carnosine (contains 2, 4, and 7)

1 $\mathrm{H}$ NMR $(300 \mathrm{MHz})$ in $\mathrm{CD}_{3} \mathrm{OD}$

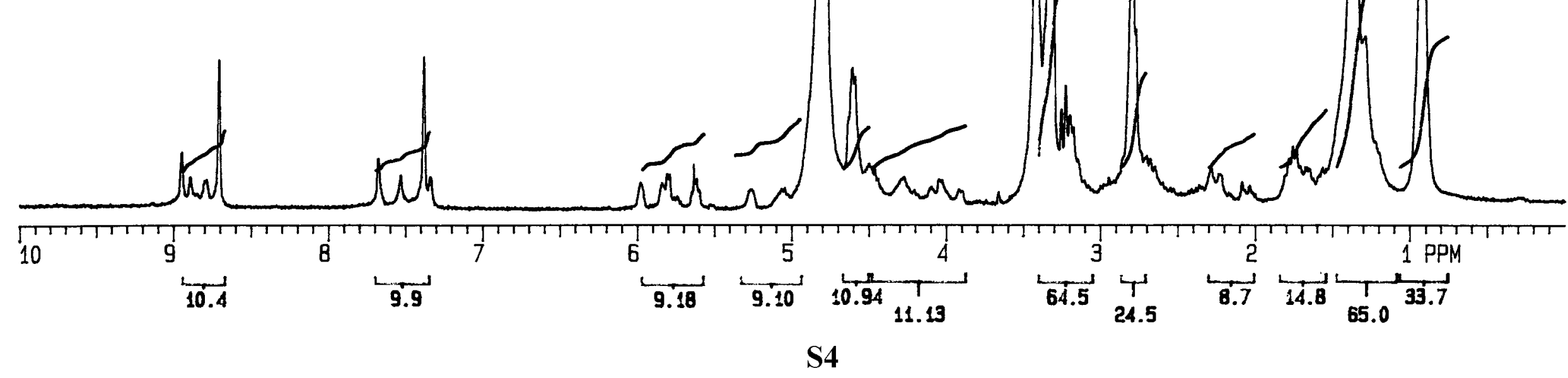


approximate $1: 7$ mixture of 9 (signals at

59 ppm) and 10 (signals at 46-47 ppm)

${ }^{13} \mathrm{C}$ APT NMR $(75 \mathrm{MHz})$ in $\mathrm{CD}_{3} \mathrm{OD}$

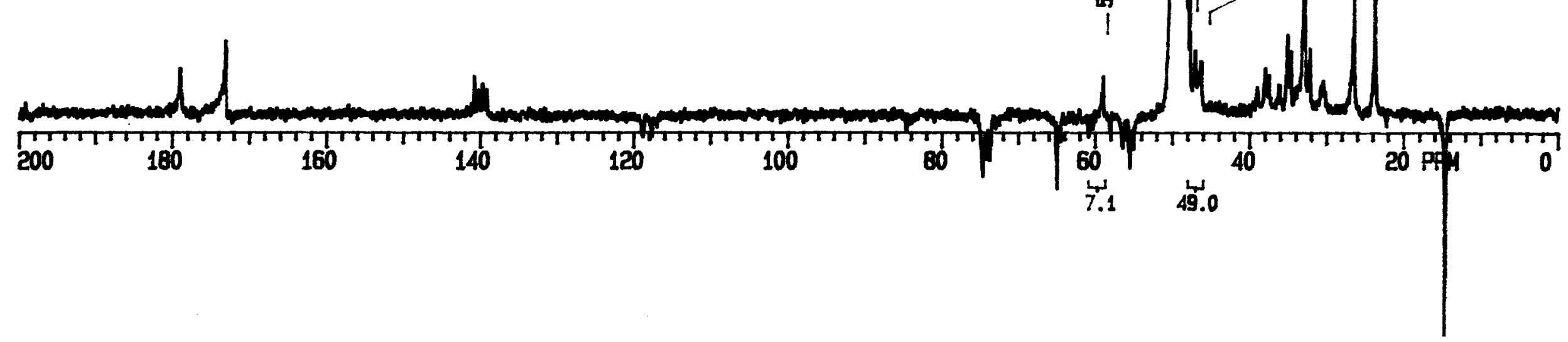




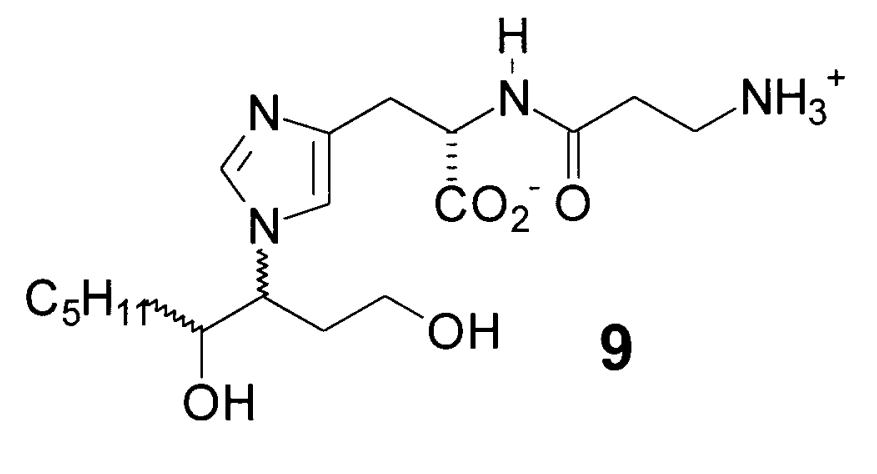

${ }^{1} \mathrm{H}$ NMR $(300 \mathrm{MHz})$ in $\mathrm{CD}_{3} \mathrm{OD}$

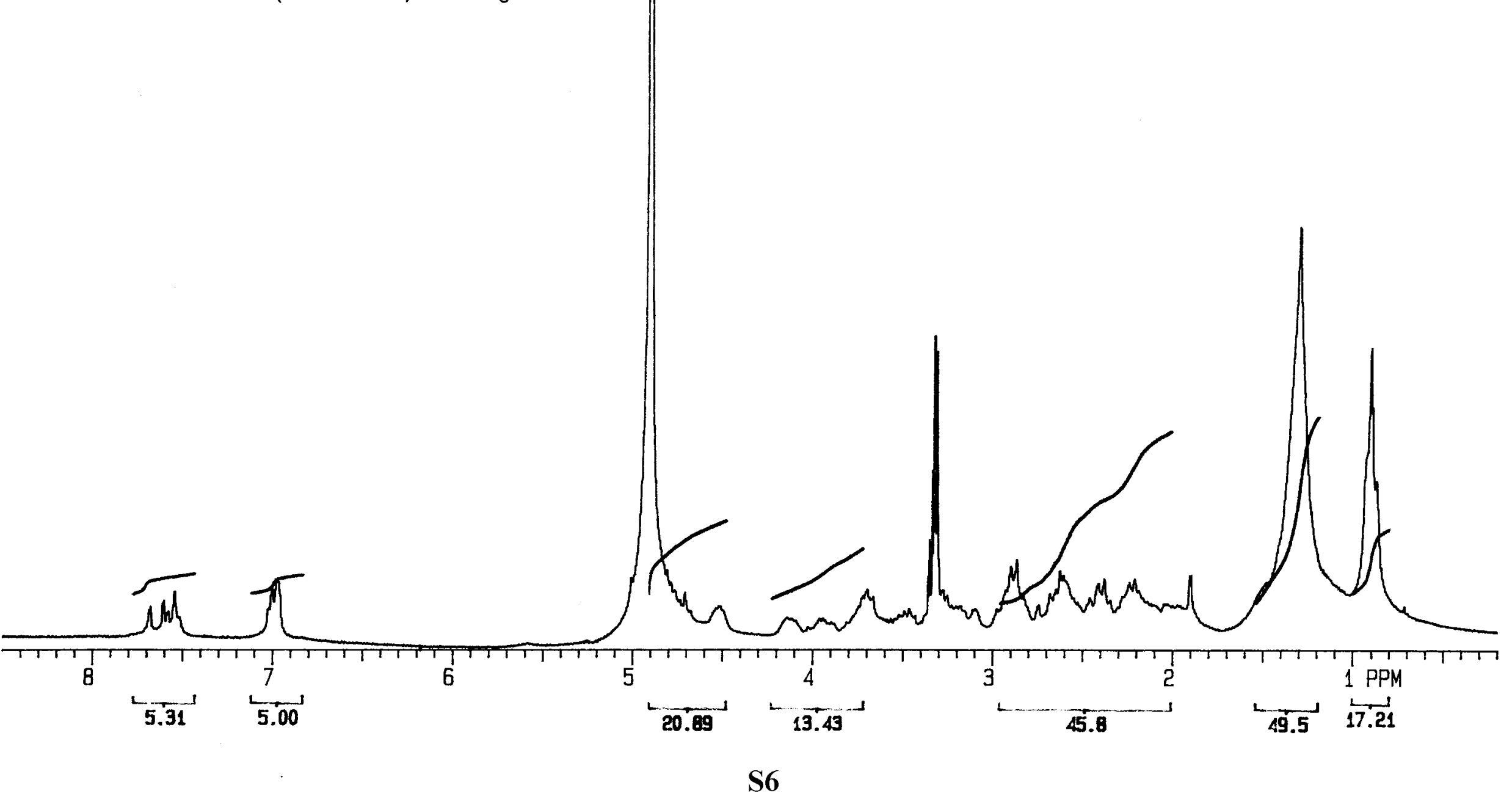




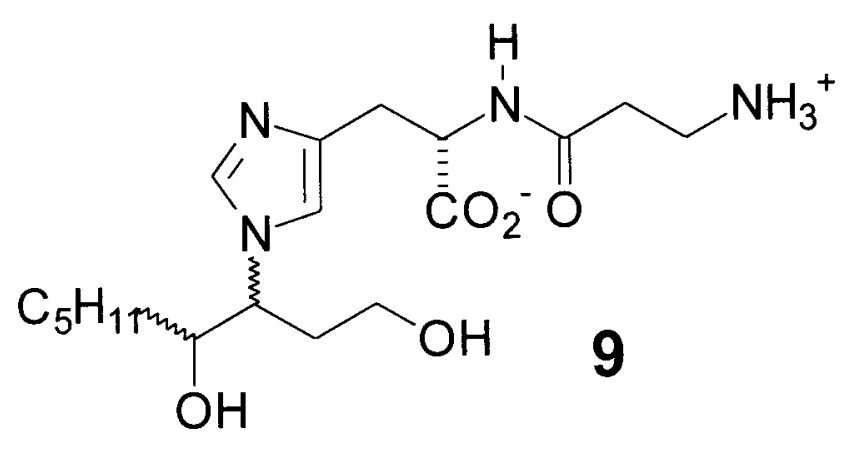

${ }^{13} \mathrm{C}$ APT NMR $(50 \mathrm{MHz})$ in $\mathrm{CD}_{3} \mathrm{OD}$

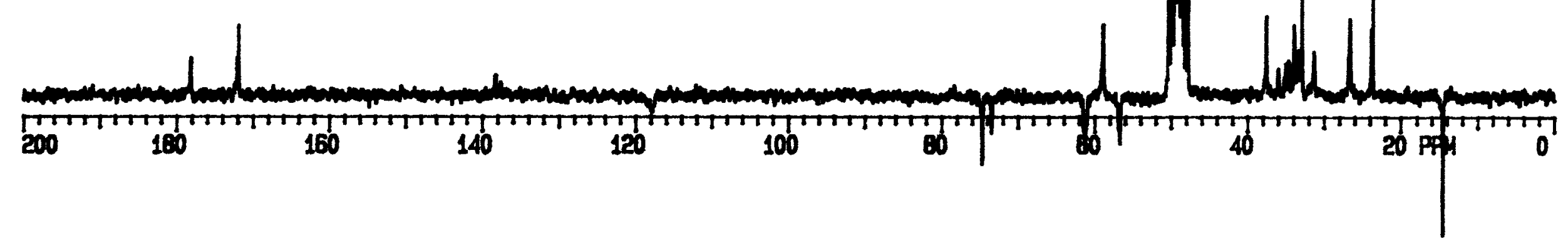




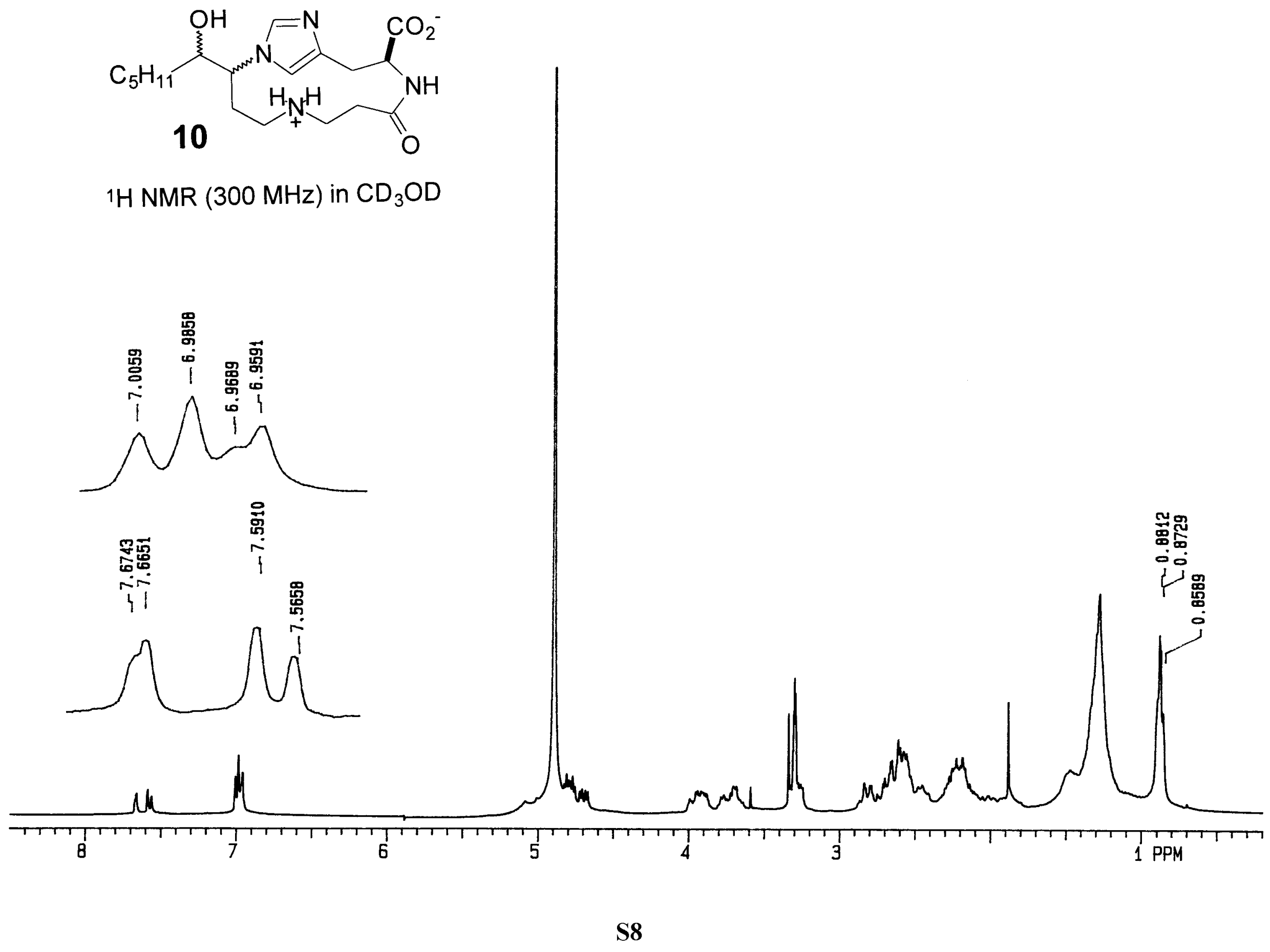




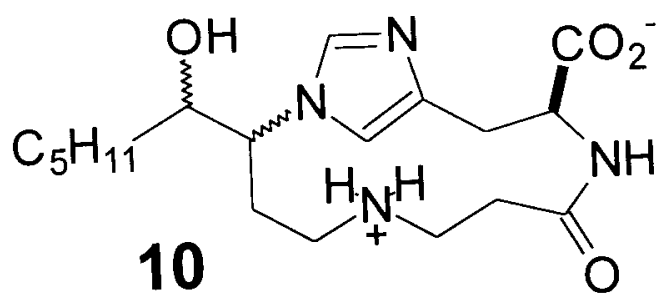

${ }_{13} \mathrm{C}$ APT NMR $(50 \mathrm{MHz})$ in $\mathrm{D}_{2} \mathrm{O}$

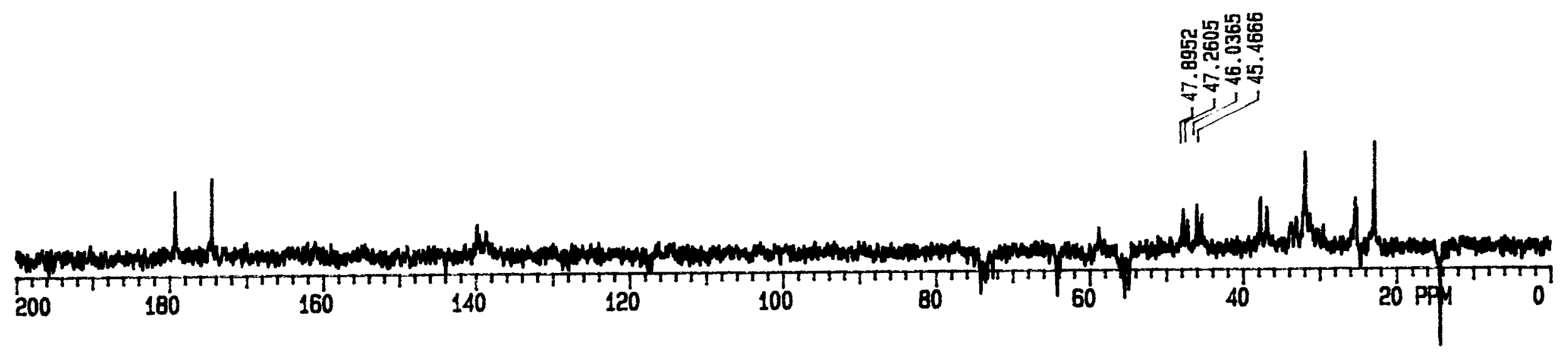




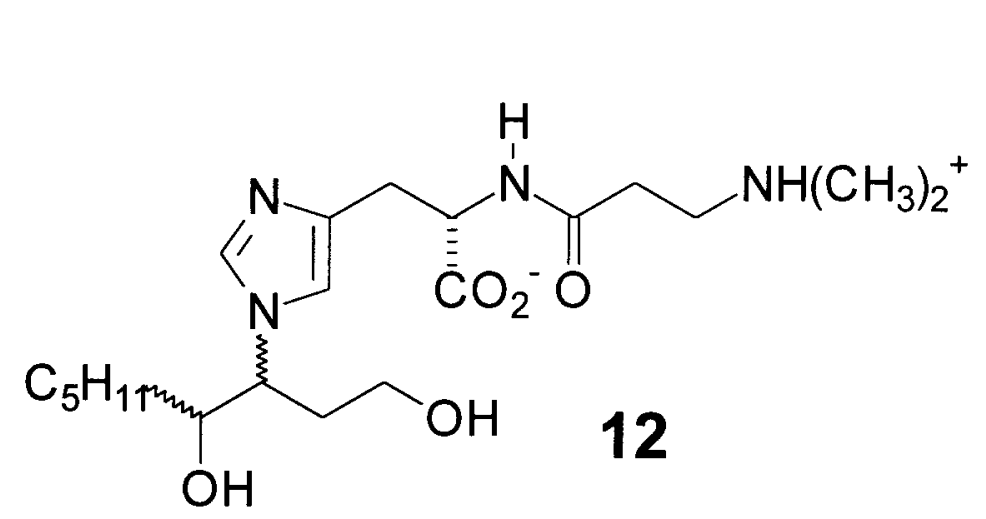

${ }^{1} \mathrm{H} \mathrm{NMR}(200 \mathrm{MHz})$ in $\mathrm{CD}_{3} \mathrm{OD}$
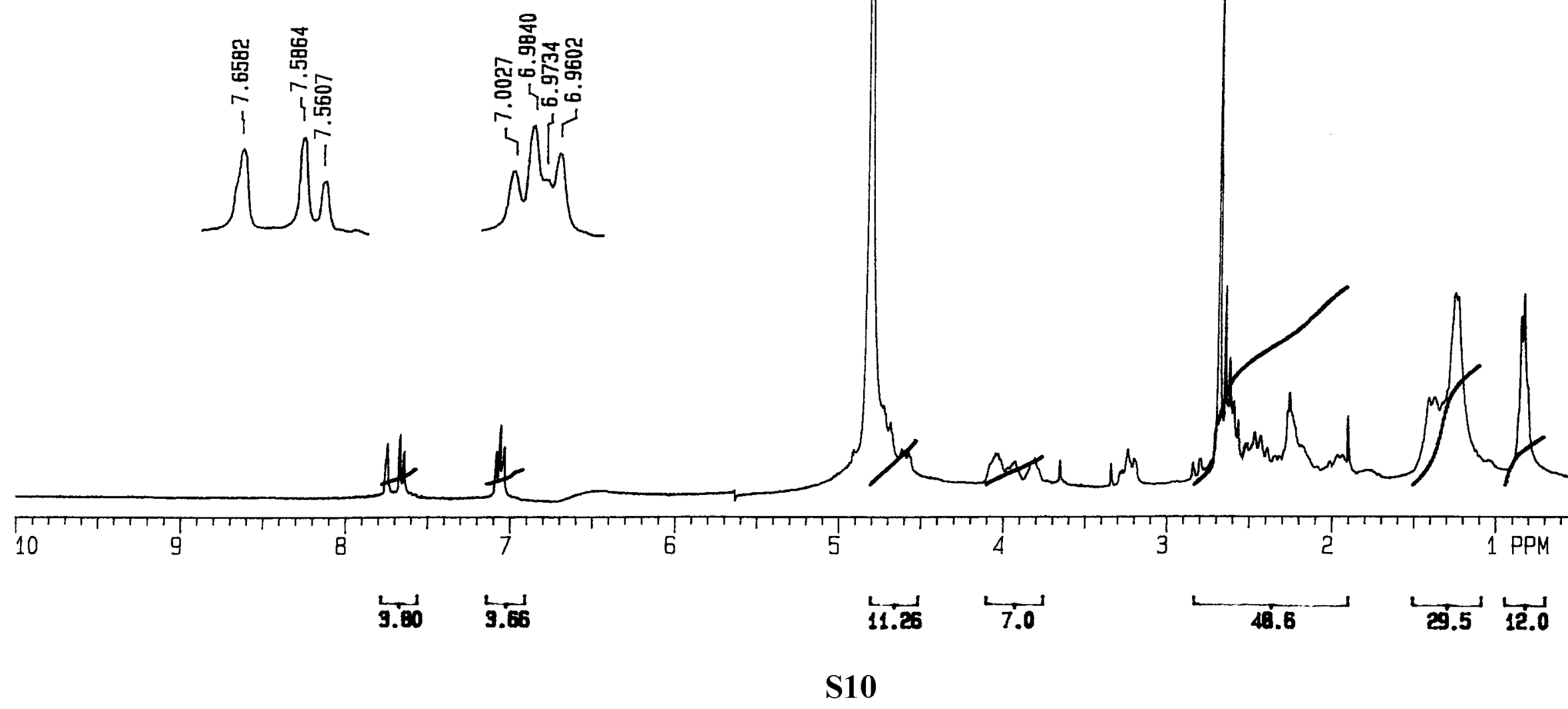


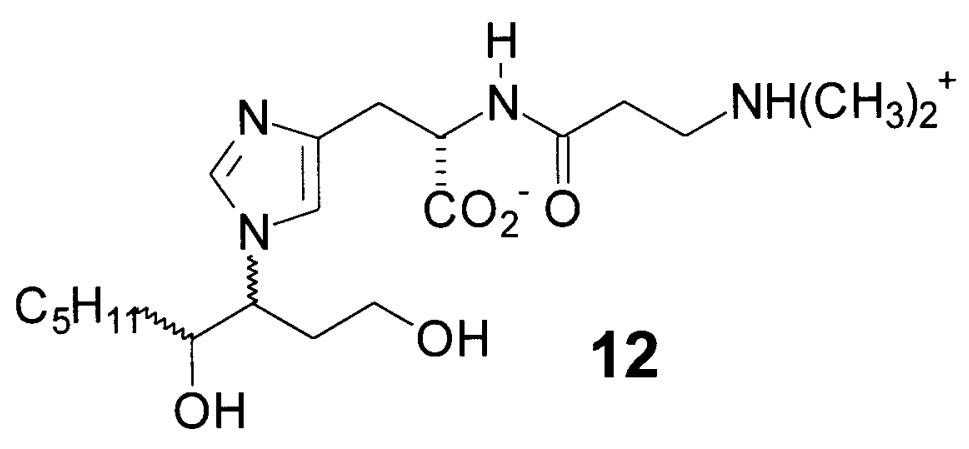

${ }^{13} \mathrm{C}$ APT NMR $(50 \mathrm{MHz})$ in $\mathrm{CD}_{3} \mathrm{OD}$

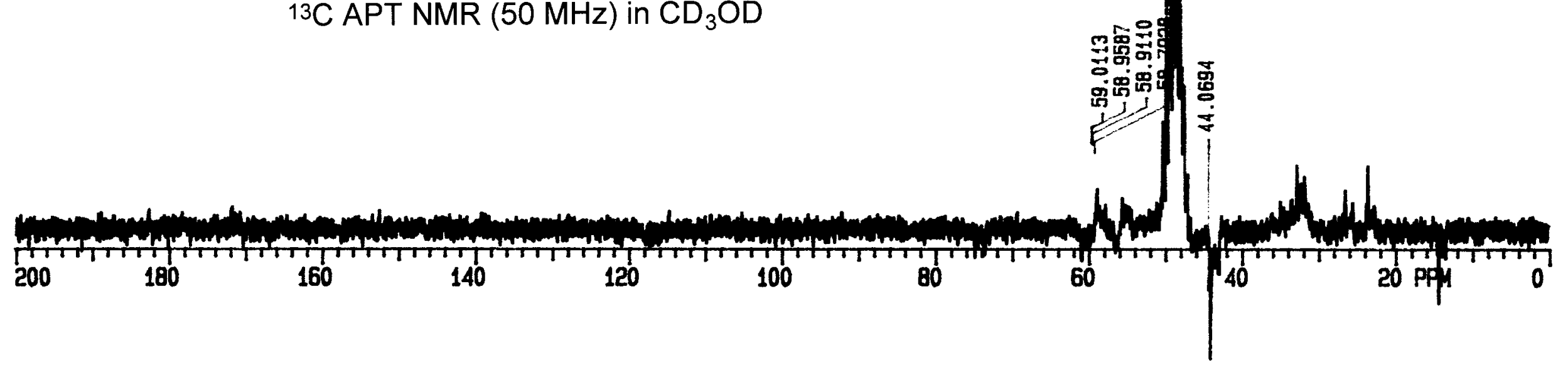




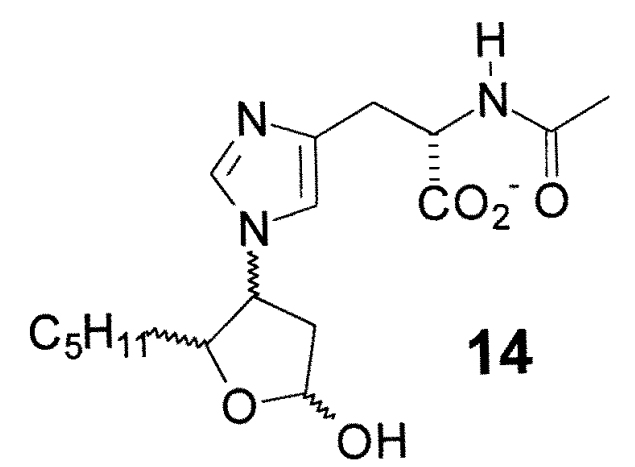

1H NMR $(300 \mathrm{MHz})$ in $\mathrm{CD}_{3} \mathrm{OD}$
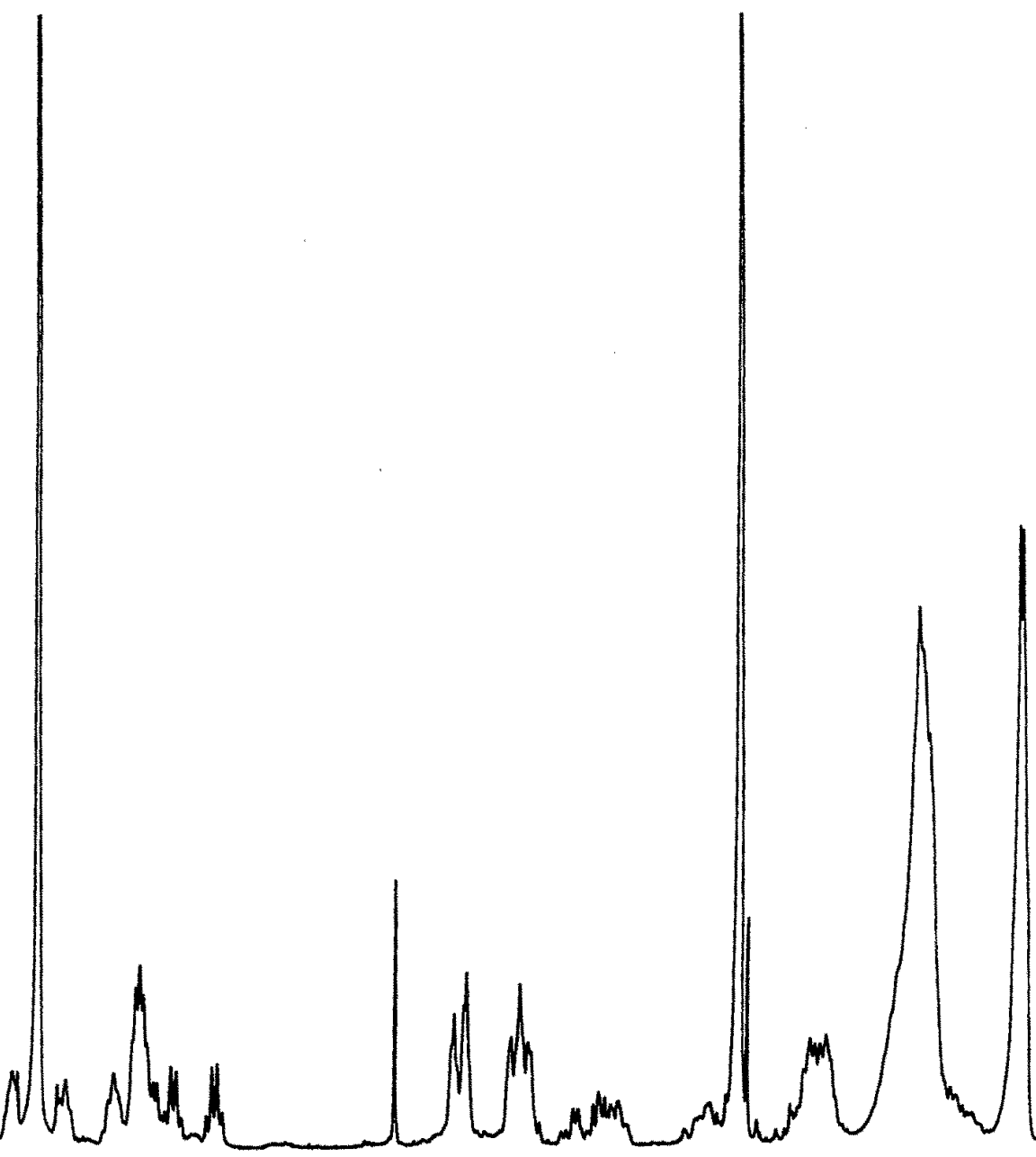

ITTTTTT

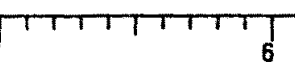

गाTा।

S12 


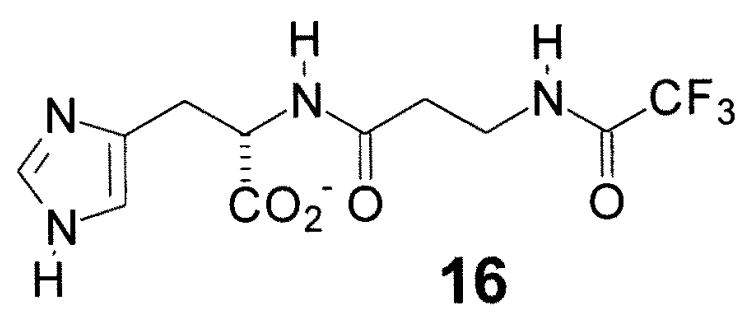

${ }^{1} \mathrm{H}$ NMR $(200 \mathrm{MHz})$ in $\mathrm{CD}_{3} \mathrm{OD}$

$\Gamma_{10}$
8
82.3
2.3

24.5

6

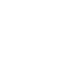

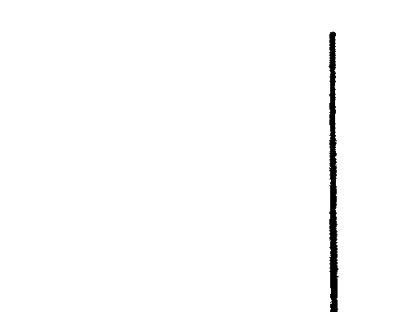


<smiles>O=C(CCNC(=O)C(F)(F)F)N[C@@H](Cc1c[nH]cn1)C(=O)O</smiles>

\section{$\mathrm{H} \quad 16$}

${ }^{13} \mathrm{C}$ APT NMR $(75 \mathrm{MHz})$ in $\mathrm{CD}_{3} \mathrm{OD}$

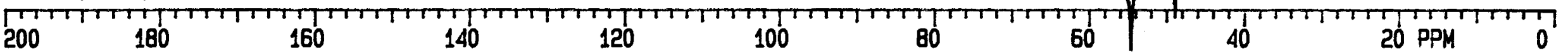




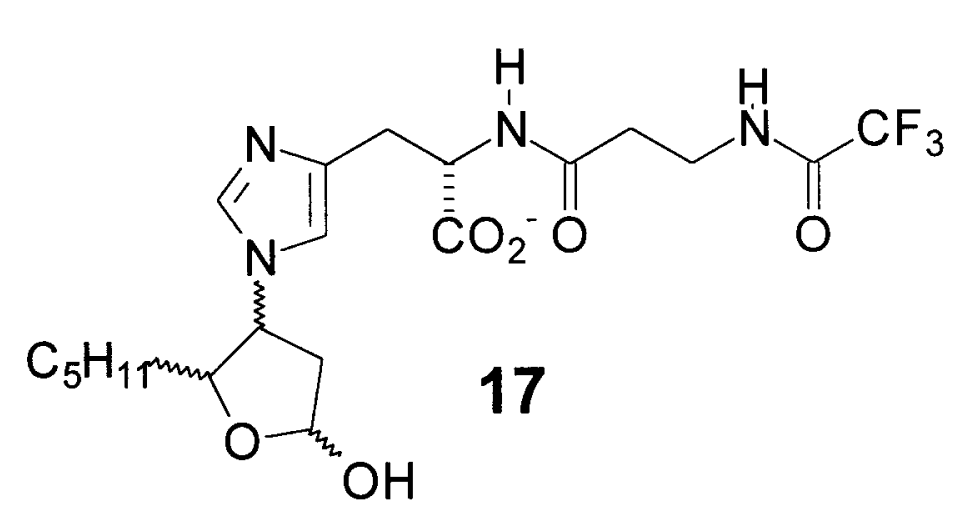

${ }_{1}^{1} \mathrm{H}$ NMR $(300 \mathrm{MHz})$ in $\mathrm{CD}_{3} \mathrm{OD}$

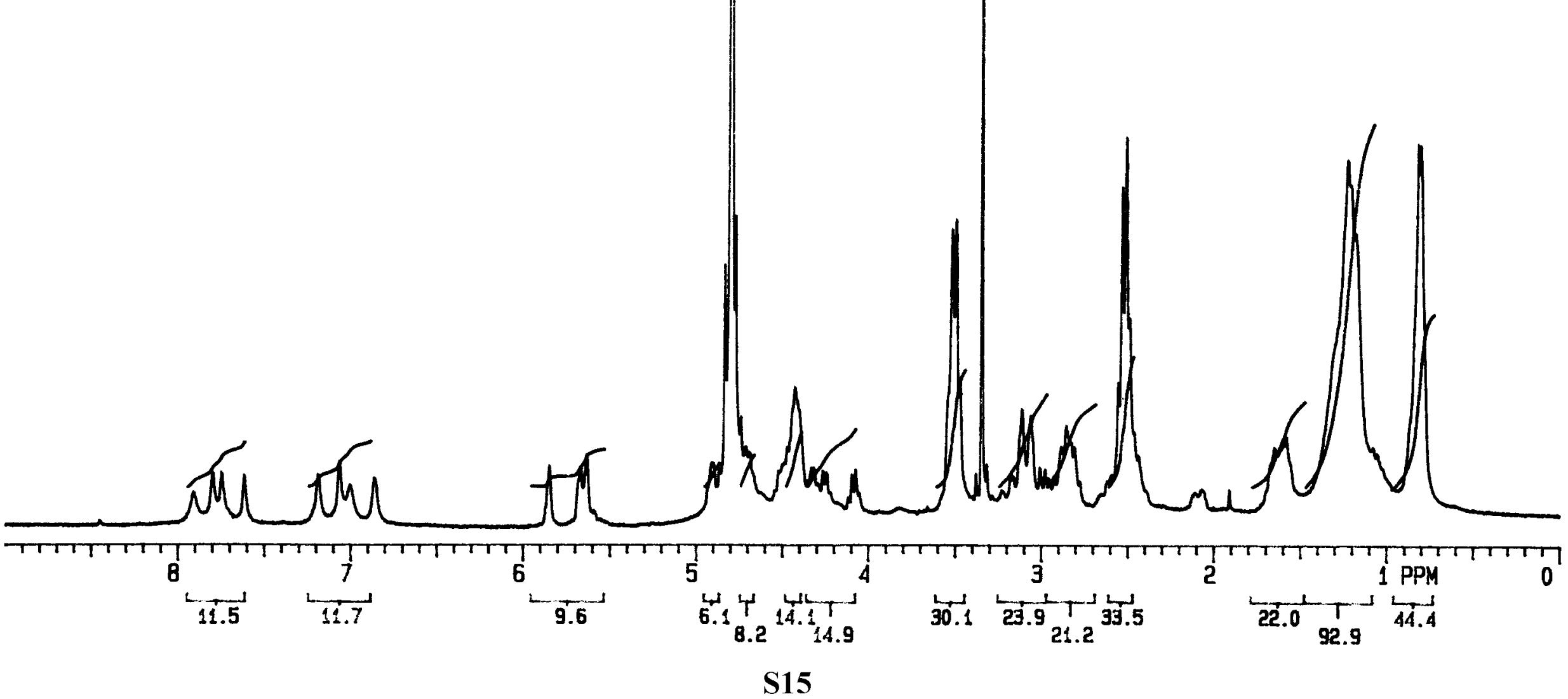

